\title{
Electrodeposition of Iron with Co-deposition of Carbon: On the Nature of Nanocrystalline Fe-C Coatings
}

Nielsen, Jacob Obitsø; Møller, Per; Pantleon, Karen

Published in:

Metallurgical and Materials Transactions A: Physical Metallurgy and Materials Science

Link to article, DOI:

$10.1007 / \mathrm{s} 11661-019-05311-z$

Publication date:

2019

Document Version

Peer reviewed version

Link back to DTU Orbit

Citation (APA):

Nielsen, J. O., Møller, P., \& Pantleon, K. (2019). Electrodeposition of Iron with Co-deposition of Carbon: On the Nature of Nanocrystalline Fe-C Coatings. Metallurgical and Materials Transactions A: Physical Metallurgy and Materials Science, 50A(8), 3785-3793. https://doi.org/10.1007/s11661-019-05311-z

\section{General rights}

Copyright and moral rights for the publications made accessible in the public portal are retained by the authors and/or other copyright owners and it is a condition of accessing publications that users recognise and abide by the legal requirements associated with these rights.

- Users may download and print one copy of any publication from the public portal for the purpose of private study or research.

- You may not further distribute the material or use it for any profit-making activity or commercial gain

- You may freely distribute the URL identifying the publication in the public portal 


\section{Electrodeposition of iron with co-deposition of carbon - on the nature of nanocrystalline \\ 2 Fe-C coatings}

3 Jacob Obitsø Nielsen*, Per Møller, Karen Pantleon

4 Technical University of Denmark, Department of Mechanical Engineering, Produktionstorvet,

5 building 425, DK - 2800 Kongens Lyngby, Denmark

$6 \quad *$ Corresponding author: jacobon@mek.dtu.dk

\section{Abstract}

9 Fe-C coatings were electrodeposited from an iron-sulfate electrolyte containing citric acid as a

10 carbon source. Differently thick coatings were deposited onto amorphous substrates, which

11 allows substrate-unbiased nucleation and thereby enables the study of the intrinsic growth of Fe-

$12 \mathrm{C}$ coatings. The internal structure of the Fe-C coating was systematically investigated applying

13 complementary methods of materials characterization using microscopy, spectroscopy, and X-

14 ray diffraction analysis, which was further supplemented with microhardness measurements. For

15 the measured high carbon concentration of more than $0.8 \mathrm{wt}$ pct, the experimental results

16 indicate the formation of $\mathrm{Fe}_{2} \mathrm{C}$ carbides. Together with the nanocrystalline carbon-free ferrite

17 grains with strong $<311>$ fiber texture, the carbides provide a very high microhardness of almost

$18800 \mathrm{HV}$, as measured for the Fe-C coatings independent of the coating thickness. The results

19 essentially contribute to understanding of the growth characteristics and phase formation during

20 electrodeposition of the Fe-C coatings, which is needed for their industrial applications as hard

21 coatings.

\section{Keywords}

23 Iron alloys, coatings, nanocrystalline materials, electrodeposition, characterization.

25 https://doi.org/10.1007/s11661-019-05311-z

26 METALLURGICAL AND MATERIALS TRANSACTIONS A, VOLUME 50A, AUGUST

$27 \quad 2019-3785$

28 Manuscript submitted November 20, 2018. Article published online June 5, 2019 


\section{INTRODUCTION}

33 Electrochemical deposition of iron from iron-sulfate baths was developed a century ago and

34 implies the advantages of a cheap electrolyte, low operating temperature and low susceptibility

35 to oxidation of the electrolyte [1]. Originally, electrodeposition of iron was mainly used for

36 short-term restoration of worn or damaged surfaces of machine components [2,3], as for these

37 applications, the ease of site-specific deposition and attractive mechanical properties of the

38 coatings were of main interest. More recently, the intended co-deposition of other elements (e.g.,

39 tungsten, nickel, phosphorous and zinc) from advanced electrolytes inspired a revival of the

40 original interest in iron-based coatings [4]. Of particular interest is the co-deposition of carbon

41 and iron, and iron-carbon ( $\mathrm{Fe}-\mathrm{C})$ coatings have been synthesized not only by electrochemical

42 deposition [5-13], but also by physical vapor deposition [14-17]. Although different

43 morphologies and structures of $\mathrm{Fe}-\mathrm{C}$ coatings ranging from amorphous to crystalline and

44 different carbon concentrations are reported for the various deposition processes, all $\mathrm{Fe}-\mathrm{C}$

45 coatings possess very high hardness, being similar to the hardness of martensite in steels. Despite

46 that similarity, the peculiarities of the growth of Fe-C coatings suggest essential differences to

47 traditional hardening of steel and, hence, a different origin of microstructure and properties.

48 Despite a general consistency in the literature regarding the good mechanical properties of Fe-C

49 coatings, their growth characteristics and, in particular, the role of carbon in the coatings are

50 aspects that not fully are understood yet. This, however, is essential for the promising application

51 of Fe-C coatings as a novel type of hard and wear-resistant surfaces, which both enables

52 straightforward repairing of worn surfaces by site-specific deposition and the large-scale

53 deposition on components exposed to mechanical loading during operation.

54 Electrodeposited Fe-C coatings have a huge potential for surface engineering, including tailoring

55 of the deposition parameters to optimize the growth characteristics and additional modifications

56 during post-deposition treatments of the coatings. Understanding the correlation between the

57 applied deposition conditions and the resulting microstructure is a prerequisite for the successful

58 transfer of knowledge obtained on laboratory scale into a reliable, reproducible, large-scale 
59 production $[18,19]$. In addition to the type of electrolyte and the process parameters, like current

60 density and temperature, both nucleation and growth of electrodeposits are further affected by

61 the nature of the substrate, which influences the size, shape, crystallographic orientation of the

62 grains, and consequently, resulting properties of the coatings. Previous studies dedicated to

63 electrochemical deposition of $\mathrm{Fe}-\mathrm{C}$ coatings refer to an iron-sulfate bath with the addition of a

64 small amount of carbon-containing organic acids [5-13]. The type of such organic additives has

65 been found to determine not only the possible amount of co-deposited carbon but also the

66 macroscopic appearance as well as the topography, morphology, and associated properties of the

67 Fe-C coatings $[7,12,13]$. In addition to the electrolyte composition, also the effect of the $\mathrm{pH}$

68 value, the deposition temperature and the applied cathode current density have been investigated

69 [5-10,12].

70 The present work reports on systematic studies of Fe-C coatings, which were electrodeposited

71 from an iron-sulfate electrolyte with citric acid as additive. To investigate the intrinsic growth

72 characteristics of the coatings, electrodeposition was carried out onto amorphous nickel-

73 phosphorous (Ni-P) substrates under identical process parameters. Only the deposition time was

74 varied to result in $\mathrm{Fe}-\mathrm{C}$ coatings with various thicknesses up to several tenths of micrometers.

75 Based on thorough materials characterization of the as-deposited coatings with a focus on their

76 internal structure and the corresponding microhardness, the incorporation of carbon in the

77 coatings is discussed, also in relation to previously reported results from the literature. The

78 present work is dedicated to the understanding of the as-deposited Fe-C coatings, which provides

79 the basis for further surface engineering either by tailoring the deposition process or subjecting

80 the as-deposited coatings to post-deposition treatments.

82 II. MATERIALS AND EXPERIMENTAL METHOD

\section{A. Electrochemical Deposition}

\section{1. Substrate}

85 Fe-C depositions were carried out on amorphous substrates, with the aim of investigating the 86 effect of the electrolyte and the applied process parameters without any additional influence on

87 the coating growth. The substrates have been obtained by pretreating low-carbon steel plates by 
electroless plating of a Ni-P film from the commercial electrolyte MacDermid Enthone VANDALOY 4100 containing 10 to 12 wt pct P. The resulting amorphous Ni-P film with a thickness of about $20 \mu \mathrm{m}$ ensures substrate unbiased growth during subsequent electrodeposition of Fe-C

91 coatings. Prior to Fe-C deposition, the Ni-P substrates were subjected to cathodic degreasing at 5

$92 \mathrm{~V}$ for 2 minutes followed by 2 minutes of surface activation in commercial dry acid $629 \mathrm{SV}$ from 93 EngTech Scandinavia.

\section{2. Deposition Parameters}

95 The electrolyte was prepared from chemicals of analytical grade with a concentration of 0.143

$96 \mathrm{~mol} / \mathrm{dm}^{3}$ iron(II) sulfate heptahydrate, $6.2 \times 10^{-3} \mathrm{~mol} / \mathrm{dm}^{3}$ citric acid monohydrate, and deionized

97 water. The $5 \mathrm{~L}$ of the electrolyte were freshly mixed for each sample to avoid any possible

98 oxidation or aging of the electrolyte as an additional influence on the microstructure and

99 properties of the Fe-C coatings. The electrolyte temperature amounted to $50{ }^{\circ} \mathrm{C}$ and mechanical

100 stirring was applied during deposition. The $\mathrm{pH}$ value of the electrolyte was maintained between

1012.5 and 2.8 during deposition using a 10 vol pct sulfuric acid solution. An interstitial free steel

102 plate was used as an anode, and the Ni-P coated plates with dimensions of $5 \times 5 \mathrm{~cm}$ were used as

103 cathodes. One side of these substrate plates was covered with an electrolyte-resistant tape to

104 ensure deposition only on the side toward the anode.

105 Electrodeposition of Fe-C coatings was carried out at a constant current density of $3.0 \mathrm{~A} / \mathrm{dm}^{2}$,

106 which was applied for various deposition times between 30 and 300 minutes. The applied

107 deposition parameters and the electrolyte composition have been optimized based on previous

108 studies on electrodeposited Fe-C coatings [5-13]. The coatings were immediately after

109 deposition rinsed in water, followed by rinsing in ethanol and then carefully dried to avoid

110 oxidation. The samples were protected from any contact with oxidizing environments during

111 storage. For subsequent microstructure analysis, the samples were cut such that only the center

112 part with homogeneous coating thickness was investigated, thus, disregarding the possibly higher

113 current density near the sample edges.

114 The designation of a sample indicates the thickness of the coating, e.g., Fe-C_30 $\mu$ m corresponds 115 to a coating of $30 \mu \mathrm{m}$ thickness deposited on the Ni-P substrate. 


\section{B. Materials Characterization}

\section{1. Chemical Analysis}

119 The carbon content in the coatings was determined using a carbon analyzer LECO CS230, which

120 measures the amount of $\mathrm{CO}_{2}$ evolved by high-frequency induction heating of the sample in an $\mathrm{O}_{2}$

121 atmosphere. The measurements were performed using an amount of $0.1 \mathrm{~g}$ of a Fe-C coating

122 removed from the substrate.

123 A depth profile of the chemical composition was obtained by means of glow discharge optical

124 emission spectroscopy (GDOES) using a Horiba equipment GD profiler 2 with Quantum XP

125 software. The instrumental settings and procedure were established based on investigations of

126 the crater profile using surface roughness measurements by $3 \mathrm{D}$ coordinate measurements with an

127 Alicona InfiniteFocus. The GDOES measurements were calibrated with multiple low-alloy steel

128 standards having different carbon contents up to $1.3 \mathrm{wt}$ pct. The content of hydrogen and oxygen

129 is given as measured intensity because these elements have not been calibrated.

130 2. Microscopic Analysis

131 Microscopic analysis was carried out on cross sections of the samples. Before cross section 132 preparation, the samples were coated with a $10 \mu \mathrm{m}$ layer of nickel to protect the surface of the

133 Fe-C coatings. Samples were embedded in epoxy resin, which hardens at room temperature and

134 avoids any risk of introducing artifacts to the as-deposited coatings. The cross sections were 135 metallographically prepared and polished with OP-S for 3 minutes as a final preparation step. An

136 Olympus GX41 light optical microscope (LOM) was used for the thickness measurements on 137 cross sections. A FEI Quanta 200 ESEM scanning electron microscope (SEM) was used for 138 investigations on the cross sections.

\section{3. X-ray Diffraction Analysis}

140 A Bruker AXS D8 Discover X-ray diffractometer equipped with an Eulerian cradle and operated 141 with $\mathrm{Cr}-\mathrm{K}_{\alpha}$ radiation was used for qualitative phase analysis, line profile analysis, and 142 quantitative crystallographic texture analysis. A Göbel mirror was used to obtain a high, intense 143 parallel beam for phase analysis and line profile analysis, while a PolyCap optics was used to 144 ensure a parallel beam for texture analysis along with a vanadium filter to avoid $\mathrm{K}_{\beta}$-radiation. 
145 The calculated information depth in iron corresponds to a maximum of about $6 \mu \mathrm{m}$ within the 146 measured range of diffraction angles between 50 and $160 \mathrm{deg} 2 \Theta$.

147 X-ray diffraction (XRD) phase analysis was carried out applying a symmetric beam path.

148 Samples were measured using a step size of $0.02 \mathrm{deg} 2 \Theta$ and a measurement time of 20 seconds 149 per step to ensure high resolution and good counting statistics. For qualitative phase analysis, the 150 measured diffraction angles were corrected for any offset related to the alignment of the 151 diffractometer using a $\mathrm{LaB}_{6}$ reference sample.

152 XRD line profile analysis was carried out for the 110, 200, and 211 reflections of $\alpha-F e$. The 153 measured diffraction patterns were fitted with a superposition of two linked pseudo-Voigt 154 functions corresponding to the $\mathrm{K}_{\alpha 1}$ and the $\mathrm{K}_{\alpha 2}$ components of the applied X-rays. Only the 155 fitting results for the $\mathrm{K}_{\mathrm{a} 1}$ component were used for interpretation. Fitting with the pseudo-Voigt 156 function revealed the following parameters for further analysis: (1) the $2 \Theta$ peak position, (2) the 157 full-width-half-maximum (FWHM), (3) the shape of the peak defined by the contribution of 158 Gaussian and Lorentzian function to the peak profile, and (4) the integrated intensity of the 159 measured peaks. The measured peak broadening was corrected for the effect of instrumental 160 broadening applying a $\mathrm{LaB}_{6}$ standard powder sample. The resulting physical peak broadening 161 was expressed as integral breadths $\beta$, calculated from the FWHM and the profile shape, and 162 subjected to the single line method for separating the simultaneous influences of the size of 163 coherently diffracting domains (interpreted as the crystallite size) and lattice microstrain on peak 164 broadening [20,21].

165 For quantitative crystallographic texture analysis by means of XRD, 110-, 200- and 211-pole 166 figures of $\alpha$-Fe were measured for all samples, applying sample rotations around the surface 167 normal (azimuth angle $\varphi, 0 \leq \varphi \leq 360 \mathrm{deg}$, step size $5 \mathrm{deg}$ ) and sample tilts (pole angle $\psi, 0 \leq \psi$ $168 \leq 75 \mathrm{deg}$, step size $5 \mathrm{deg}$ ). Measured intensities were corrected for background intensity, and a 169 Fe-powder standard was used to correct for defocusing associated with tilting. For texture 170 quantification, the orientation distribution function was calculated in MTEX using the zero-range 171 method [22]. The maxima in the inverse pole figures in normal direction to the substrate were 172 used to determine the fiber axis $\langle\mathrm{uvw}>$, as ideal fiber textures apply for all Fe-C coatings. 173 Inverse pole figures in directions within the plane of the coating revealed random rotations 
174 around the fiber axis. Accordingly, the corresponding orientation densities in the normal

175 direction are a measure of the texture strength.

\section{Microhardness Measurements}

177 The microhardness was measured using a Future Tech Inc. FM700 microhardness tester with

178 Vickers geometry, applying a load of $10 \mathrm{~g}$. Measurements were performed both on the surface

179 and on metallographically prepared cross sections. Microhardness measurements on the surfaces

180 of all samples represent averages over 20 measurement positions, while results from

181 measurements on the cross sections correspond to 10 indentations in the middle of the coating.

\section{III. RESULTS}

\section{A. Microscopic Analysis of Fe-C Coatings}

184 Microscope investigations of the cross sections indicate uniform coatings with homogeneous 185 coating thicknesses, as shown in Figure 1 on the example of sample Fe-C_58 $\mu \mathrm{m}$. While the 186 surface roughness of the original steel substrate is still maintained in the Ni-P substrate layer (cf. 187 Figure 1(a), steel-Ni-P and Ni-P-Fe-C interfaces), a leveling effect occurs during the growth of 188 the Fe-C coating resulting in a smooth surface (cf. Figure 1(a), interface Fe-C-Ni). The figure 189 indicates that the surface roughness of the Fe-C coating considerably decreased already at a 190 thickness of $16 \mu \mathrm{m}$ and the surface fully leveled out for coating thicknesses of $30 \mu \mathrm{m}$ and above. 191 The cross sections also revealed that the microstructure is very fine grained and cannot even be 192 resolved with SEM (cf. Figure 1(b)).
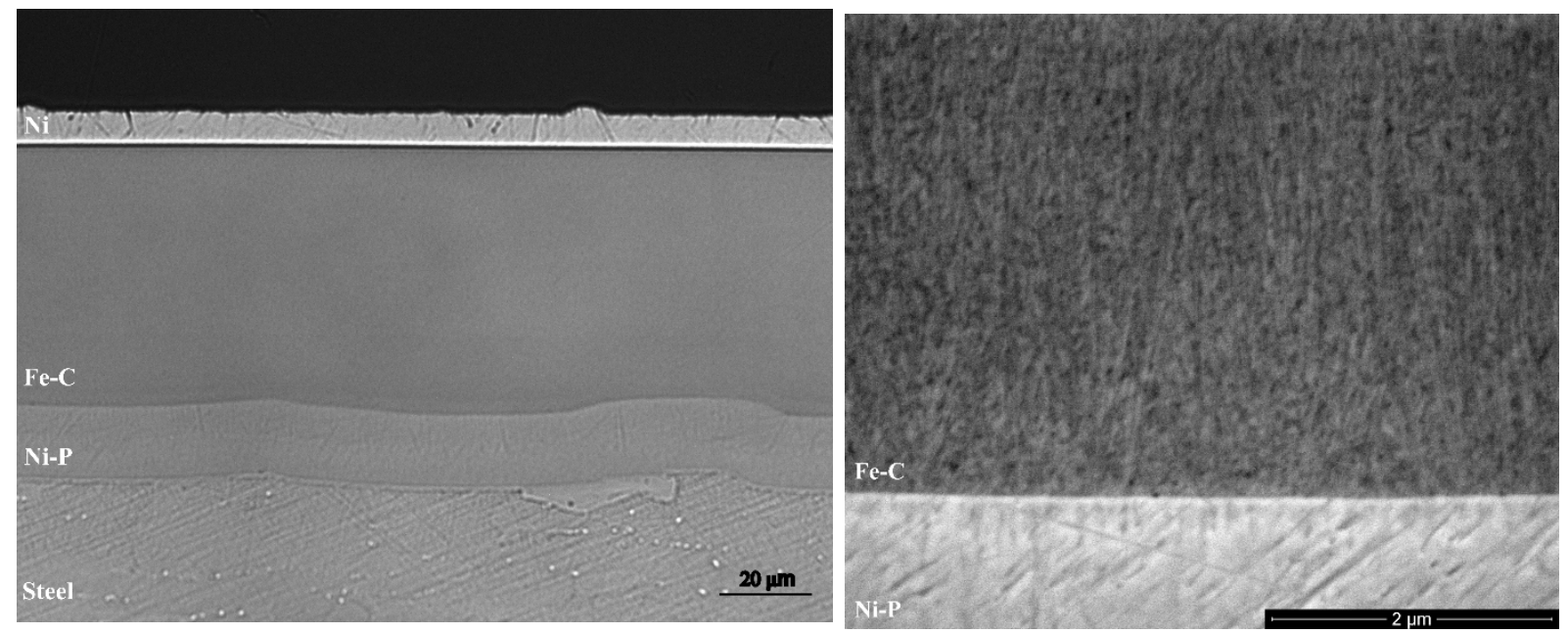
194 Figure 1: Cross section of sample Fe-C_58 5 m. Ni-P corresponds to the amorphous substrate layer

195 on top of steel, while a Ni film protects the surface of the Fe-C coating during metallographic

196 preparation. a) LOM image, b) SEM image.

197 Although neither LOM nor SEM can resolve the very fine-grained microstructure of the Fe-C

198 coatings, microscopy of the various cross sections revealed the thickness of the Fe-C coatings as a

199 function of the applied deposition time, which allowed calculation of the deposition rate. The

200 results shown in Table I indicate that the deposition rate is highest with $0.27 \mu \mathrm{m} / \mathrm{min}$ at the

201 beginning of the deposition, thus, for the thinnest coatings and drops to $0.19 \mu \mathrm{m} / \mathrm{min}$ for the

202 thickest coating of the present study.

\section{B. Chemical Analysis}

205 Chemical analysis applying the LECO system determined the carbon concentration to be $0.88 \pm$

$2060.02 \mathrm{wt}$ pct, which represents an average value over the whole thickness of a coating. The

207 presence of such a high carbon concentration is confirmed by GDOES, which further

208 supplements with the depth distribution of relevant elements like carbon, oxygen, and hydrogen.

209 In the depth profiles shown on the example of sample Fe-C_16 $\mu \mathrm{m}$ in Figure 2, the first few

210 micrometers should be disregarded as they relate to the running-in period during sputtering from

211 the surface. The interface between the Fe-C coating and the substrate, seen as a drop in carbon,

212 oxygen, and hydrogen concentrations, is obtained after a total time of about 160 seconds, which

213 corresponds to a sputter depth of $22 \mu \mathrm{m}$. A homogenous distribution of carbon is measured

214 across the coating thickness. In addition, significant intensities are measured for hydrogen and

215 oxygen, which reveal that these elements are present in the coatings, although they cannot be

216 quantified. The slightly decreasing content of hydrogen could be an artifact from the sputtering

217 process and local heating of the measured region, which would result in a higher concentration in

218 the beginning of the measurement when hydrogen may diffuse toward the surface. 


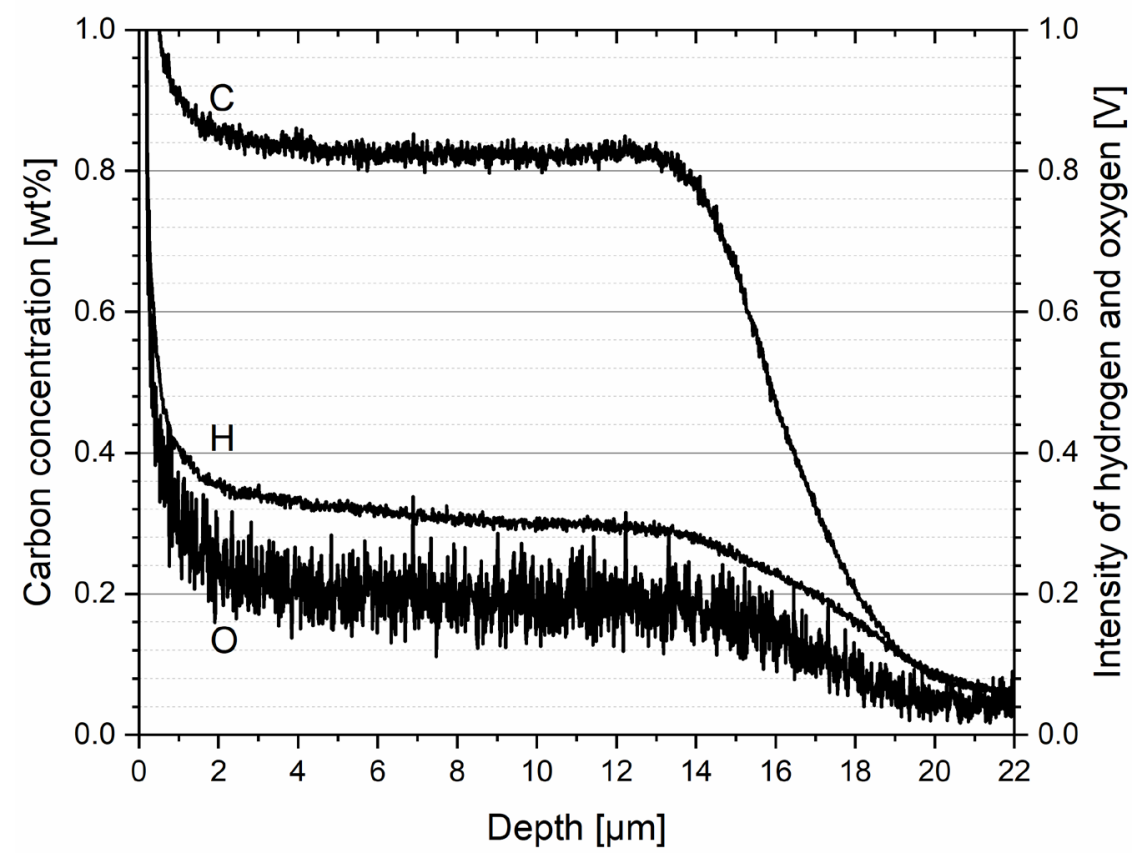

Figure 2: GDOES depth profile measured for the sample Fe-C_16 $16 \mathrm{~m}$. The concentration of 221 carbon refers to the left y-axis, while measured intensities for hydrogen and oxygen refer to the 222 right $\mathrm{y}$-axis.

\section{C. X-ray Diffraction Analysis}

225 The XRD patterns of the Fe-C coatings are shown in Figure 3 and clearly reveal the presence of $226 \alpha$-iron (JCPDS card 6-696). Depending on the coating thickness, the various reflections show 227 different intensity ratios indicating slight changes of the preferred grain orientation with coating 228 thickness. Also, independent of the thickness, further peaks in addition to the ones from the $\alpha$ 229 iron phase are observed for the measured samples at about $58.05 \operatorname{deg} 2 \Theta, 137.59 \operatorname{deg} 2 \Theta$ and $230150.73 \mathrm{deg} 2 \Theta$ (an additional peak at $126.5 \mathrm{deg} 2 \Theta$ should be disregarded because it refers to the $231 \mathrm{~K}_{\beta}$ radiation, which has not been filtered out). While the peak around $58.05 \mathrm{deg} 2 \Theta$ is of highest

232 intensity and free-standing, the other peaks are less distinct and hardly visible with only small 233 intensity in the wide tails of the $\alpha$-iron peaks (cf. inserts in Figure 3). Such weak and overlapping 234 peaks considerably complicate straightforward phase analysis for the present $\mathrm{Fe}-\mathrm{C}$ coatings.

235 Thorough peak fitting was carried out, also for the overlapping and weak peaks, and the resulting 236 d-spacings of all fitted peaks are shown in Table II. The table reveals that all peaks shift slightly 
237 toward larger d-values when the thickness of the coating increases from $8 \mu \mathrm{m}$ to $30 \mu \mathrm{m}$, without 238 remarkable further changes at $58 \mu \mathrm{m}$. Such changes of d-values suggest changes of residual 239 stresses and/or chemical changes in the coatings. As that observed shift toward larger d-values 240 with increasing thickness is most pronounced for the first two peaks (cf. Table II), another 241 observation seems particularly interesting in this respect. Table II indicates a correlation between

242 these two peaks, thus, the 110 reflection of $\alpha$-iron and the peak of the yet unidentified phase 243 having a d-spacing of about $0.236 \mathrm{~nm}$ : irrespective of the coating thickness, the ratio of the

244 lattice spacing between both peaks remains constant with $1.163 \pm 0.001$.

245 Similar challenges with phase identification, as encountered in the present work, have been 246 reported in literature, but inconsistent conclusions on the crystalline phases in the Fe-C coatings

247 indicate that the nature of growth and phase formation in such electrodeposits is still under 248 discussion. While there is general agreement in the literature (and the present work) that the 249 peaks of highest intensity in the measured diffraction patterns refer to an iron-rich phase, 250 different explanations for the presence of carbon and the corresponding formation of carbon251 containing phases have been reported [5-9,14,15,23]. The various hypotheses for the presence of 252 carbon in the Fe-C coatings are discussed and verified for the present samples below (see Section 253 IV). 


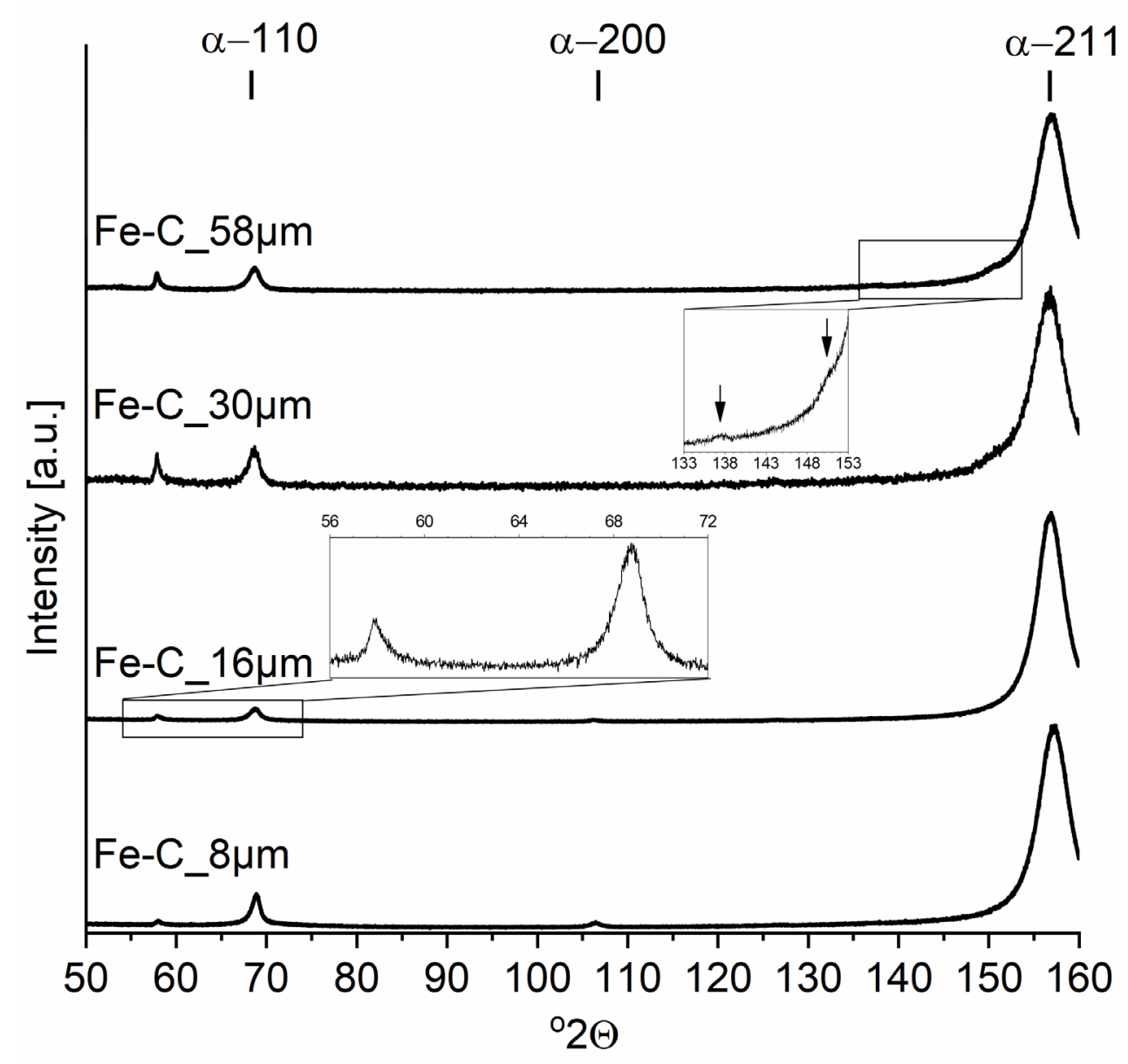

Figure 3: X-ray diffraction pattern of Fe-C coatings. (The maximum value of $160^{\circ} 2 \Theta$

corresponds to the upper limit of the measurement range and, therefore, the broad $\alpha-211$ cannot be recorded completely.)

254 All Fe-C coatings have in common that the 211 reflection of $\alpha$-iron is of highest intensity in the

$255 \Theta-2 \Theta$ scans, the 110 of $\alpha$-iron is clearly visible, and the 200 reflection of $\alpha$-iron is of very low

256 intensity or fully absent. Comparing the measured intensity ratios with the JCPDS card of

257 randomly oriented $\alpha$-iron, the presence of a pronounced preferred orientation of grains in the $\mathrm{Fe}$ -

258 C coating is obvious. For its quantification, crystallographic texture analysis by means of pole

259 figure measurements has been carried out. For all Fe-C coatings, the pole figures revealed the

260 presence of fiber textures with rotational symmetry of the measured intensity distributions as

261 shown in Figure 4 on the example of sample Fe-C_16 $\mu \mathrm{m}$. For fiber textures, inverse pole figures

262 in normal direction straightforwardly allow quantification of the fiber axis, which describes the

263 preferred orientation in the growth direction of the coatings. All Fe-C coatings consist of a $\langle 311\rangle$ 
264 fiber texture, as shown in Figure 5. The fiber axis $\langle u v w\rangle$ and the corresponding orientation 265 densities in multiples of random distribution are summarized for all samples in Table III. 266 Although the $\langle 311\rangle$ fiber axis is rather strong for all coatings, slight changes of the texture 267 strength are observed as a function of coating thickness: The strength of the $\langle 311\rangle$ increases 268 slightly with coating thickness.

269
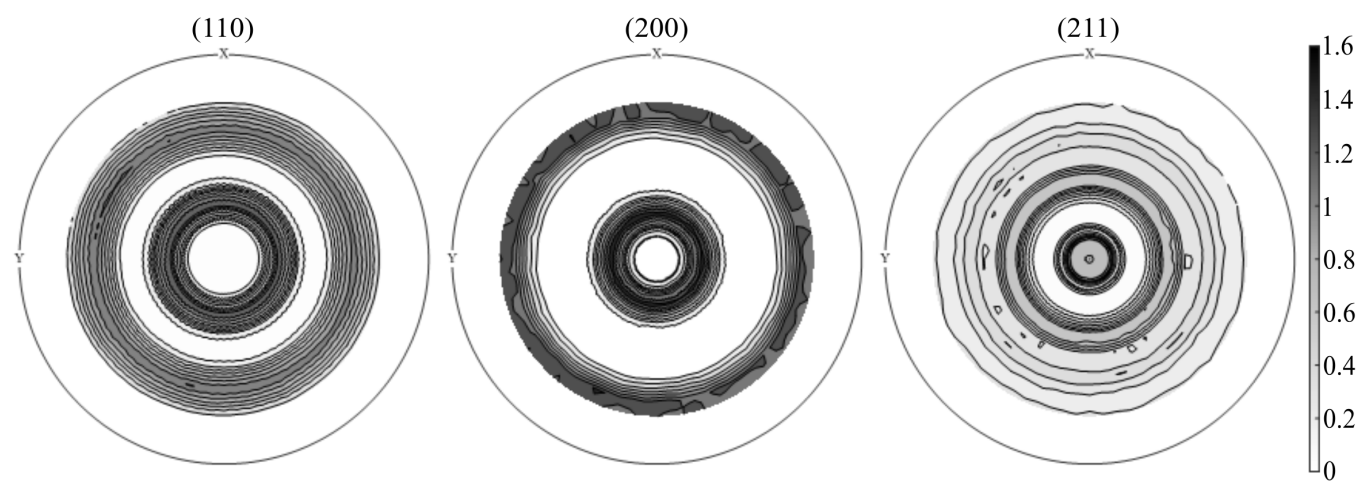

270 Figure 4: Pole figures of $\alpha$-iron as measured by XRD for the sample Fe-C_ $16 \mu \mathrm{m}$.
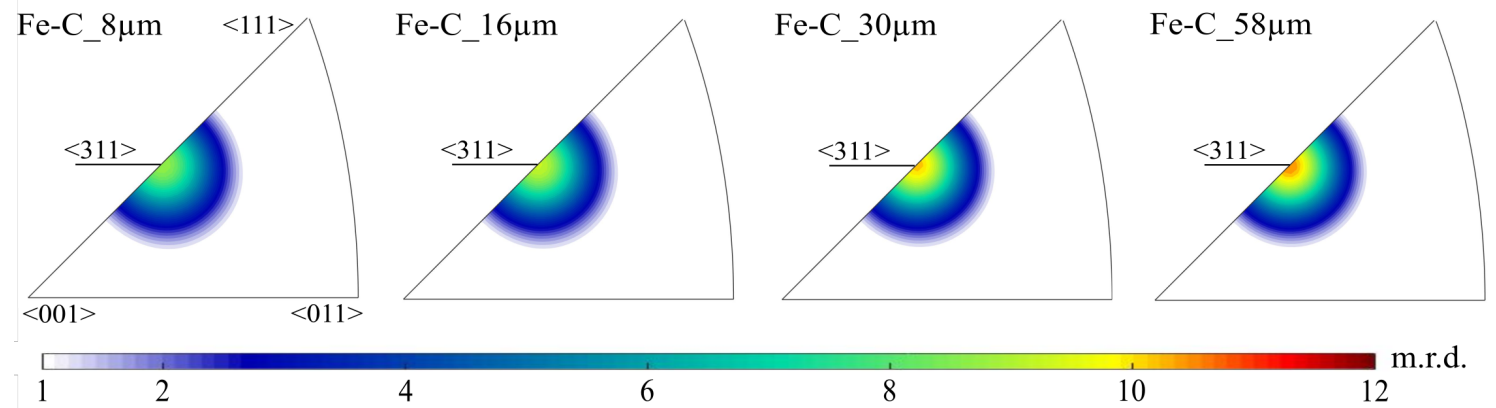

4

6

10 12

272 Figure 5: Inverse pole figures in growth direction obtained by XRD measurements.

274 It would be of interest to further analyze the $\langle 311\rangle$ oriented grains as they represent the majority 275 of grains in the Fe-C coatings, but as the 311 is a forbidden reflection for the bcc $\alpha$-iron, it is not 276 accessible from a $\Theta-2 \Theta$ scan. Instead, the 211 reflection (corresponding to grains deviating by 277 about $10 \mathrm{deg}$ from the real $\langle 311\rangle$ preferred orientation) shows the highest intensity in the 278 diffraction pattern, but it does not allow for accurate peak profile analysis. Due to substantial 279 peak broadening, the 211 exceeds the available measurement range (only up to $160 \operatorname{deg} 2 \Theta$ can 280 be measured by conventional XRD); thus, it cannot be recorded completely, and weak peaks of a 281 second phase overlap with the left tail at lower $2 \Theta$ of the 211 peak. Both hinders thorough peak 
282 profile analysis of the 211 peak, and therefore, only the 110 peak of $\alpha$-iron has been used for 283 quantification of both crystallite size and microstrain from the measured peak profiles.

284 Accordingly, the corresponding results in Table IV do not represent the average over all grains of 285 the Fe-C coatings, but instead they reflect data for $\langle 110\rangle$-oriented grains only, which constitute a 286 minority of all grains. The crystallite size of $\langle 110\rangle$ grains is in the order of about $10 \mathrm{~nm}$ and does 287 not change with coating thickness. The microstrain evolves with coating thickness, and shows a 288 sudden change in the thickness range between 16 and $30 \mu \mathrm{m}$.

\section{Microhardness}

291 High microhardness values of almost $800 \mathrm{HV} 0.01$ have been measured for all Fe-C coatings, 292 almost independent of the coating thickness, as shown in Table V. Microhardness measurements 293 on the cross sections verified the high microhardness of $\mathrm{Fe}-\mathrm{C}$ coatings.

\section{DISCUSSION}

296 The chemical analysis revealed co-deposition of carbon with an average concentration of $0.88 \pm$ 2970.02 wt pct $\mathrm{C}$ and indicates that oxygen and hydrogen are present in the Fe-C coatings (cf. Figure 298 2). These elements certainly originate from the citric acid in the electrolyte, although hydrogen 299 also might be caused by hydrogen evolution, which is a typical phenomenon occurring during 300 electrodeposition. Despite intensive attempts applying various methods of dedicated high301 resolution microscopy and element analysis, it remains challenging to quantify and locate the co302 deposited hydrogen and oxygen in the coating, and this work will continue. The reducing nature 303 of the interface between cathode and electrolyte is likely either to decompose citric acid into 304 smaller fragments of a carboxylic form or to result in the incorporation of species in their 305 elemental form in the microstructure of the Fe-C coatings. Then, they would likely react with 306 iron, producing hydroxides, oxides, or carbides. In thermodynamic equilibrium, none of these 307 elements (carbon, oxygen, hydrogen) is expected to be in solid solution in $\alpha$-iron, which is 308 unambiguously identified by XRD.

$309 \mathrm{XRD}$ also revealed that the microstructure of $\alpha$-iron is nanocrystalline with crystallite sizes just 310 below $10 \mathrm{~nm}$ for the $<110>$-oriented grains. Neither coarsening of the nanocrystalline grains as a 
311 function of coating thickness nor any growth selection from the interface toward the surface has

312 been observed by XRD or SEM. Although the nanocrystalline nature of the coatings would allow

313 segregation of elemental carbon (and oxygen and hydrogen) in the numerous grain boundaries,

314 the present study does not allow for such a conclusion, and dedicated high-resolution microscopy

315 with chemical analysis at grain boundaries is in progress. The present study, however, clearly

316 indicates a second phase, in addition to $\alpha$-iron, as revealed by the additional peaks shown in

317 Figure 3 and quantified in Table II. Also, being of low intensity and partly overlapping with

318 peaks of $\alpha$-iron, which considerably complicates straightforward phase analysis, the origin of

319 these additional peaks, having d-spacings of $0.2360 \mathrm{~nm}, 0.1228 \mathrm{~nm}$, and $0.1183 \mathrm{~nm}$, has to be

320 discussed.

321 The co-deposited oxygen cannot solely explain these peaks, which do not match with $\mathrm{Fe}_{2} \mathrm{O}_{3}$

322 (hematite) or $\mathrm{Fe}_{3} \mathrm{O}_{4}$ (magnetite), and the presence of hydrogen does not refer to any phase related

323 to these peaks without speculations. However, the location of carbon, which has been measured

324 with a high concentration of more than $0.8 \mathrm{wt}$ pct $\mathrm{C}$ in the as-deposited coatings, has not been

325 explained yet. It also is not consistently reported in the literature, although similar experimental

326 results have been obtained. The following possibilities can be discussed and will be related to the

327 present results.

328 In early studies of Fe-C coatings [6-9], observations of peak asymmetries have been related to a

329 supersaturation of the bcc $\alpha-\mathrm{Fe}$ (ferrite) phase resulting in a tetragonal distortion of the iron

330 lattice corresponding to the bct $\alpha^{\prime}$-Fe (martensite) phase. For the well-known formation of

331 martensite in steel, the tetragonal distortion of the lattice originates from the preferred

332 incorporation of carbon on octahedral interstitial lattice sites in the z-axes compared to the $\mathrm{x}$ - and

$333 \mathrm{y}$-axes, which for steels is a consequence of the diffusionless transformation from the fcc iron

334 lattice (austenite) [24]. This explanation for tetragonal martensite and the corresponding peak

335 asymmetry due to the presence of double reflections of 101 and 110 for $\alpha^{\prime}$-Fe, however, does not

336 apply for the present electrodeposited samples, where there is no obvious reason for a preferred

337 occupancy of interstitial sites with carbon along one particular direction only. Furthermore, the

338 high concentration of carbon in the present samples would cause a remarkable peak splitting due

339 to the high tetragonal distortion of the lattice. Such splitting of the iron peaks into two distinct

340 peaks, which are apart from each other according to the lattice expansion/contraction in $\mathrm{z}$ - or $\mathrm{x}$ - 
341 and y-direction, has not been observed by XRD (cf. Figure 3). If, instead, carbon would be 342 incorporated with equal probability on all interstitial sites, the strong supersaturation of the 343 lattice would cause a remarkable peak shift in XRD. Large supersaturation of bcc $\alpha$-Fe with 344 carbon has been reported for vapor-deposited films (up to $5 \mathrm{wt}$ pct) $[14,15]$ and in steels after severe deformation [25], thus, for nonequilibrium states. Although electrodeposition often does not provide thermodynamic equilibrium and, thus, favors the formation of nonequilibrium

347 phases, there is no experimental evidence for the present $\mathrm{Fe}-\mathrm{C}$ coatings that carbon is in a supersaturated solid solution in the $\alpha$-Fe phase. For determining the undisturbed lattice spacing even in the potential presence of stresses, XRD has been performed in the strain-free direction of the Fe-C coating (by tilting the sample around the azimuth angle of $\psi_{0}=41.43 \mathrm{deg}$ ) and has revealed the lattice spacing of the (110) crystallographic planes with $d_{0}=0.2026 \mathrm{~nm}$, which agrees exactly with data for carbon-free $\alpha-F e$ (JCPDS card 6-696) and rejects the possibility of any carbon-supersaturation of the $\alpha-F e$ lattice. The high concentration of carbon is therefore

354 likely to have caused precipitations, as discussed below.

355 Consistent with recent studies on Fe-C coatings [5,13,23] is the present observation of an 356 additional peak corresponding to a lattice spacing of $\mathrm{d}=0.2360 \mathrm{~nm}$ (cf. Figure 3 and Table II).

357 Phase analysis has mainly to be based on that peak because it is the only one (in addition to the 358 peaks of $\alpha-\mathrm{Fe}$ ) that is of high intensity and not overlapping with others. Further peaks 359 corresponding to d-spacings of 0.1228 and $0.1183 \mathrm{~nm}$ indicating a second phase can support 360 various hypotheses for phase identification. In the following, the presence of carbides is 361 discussed.

362 For carbon-steels, $\mathrm{Fe}_{2} \mathrm{C}$ carbides can exist as either hexagonal $\varepsilon-\mathrm{Fe}_{2} \mathrm{C}$ (JCPDS card 36-1249) or 363 orthorhombic $\eta-\mathrm{Fe}_{2} \mathrm{C}$ (JCPDS card 37-999), both being transition carbides toward the formation 364 of $\mathrm{Fe}_{3} \mathrm{C}$ at higher temperatures [26-29]. Both $\varepsilon-\mathrm{Fe}_{2} \mathrm{C}$ and $\eta-\mathrm{Fe}_{2} \mathrm{C}$ are very similar to each other, 365 and earlier in the literature [5], $\varepsilon-\mathrm{Fe}_{2} \mathrm{C}$ was reported for $\mathrm{Fe}-\mathrm{C}$ coatings. The actual lattice 366 parameters of the transition carbides have been reported to be alloy specific [30] and can 367 therefore vary slightly. The $\varepsilon-\mathrm{Fe}_{2} \mathrm{C}$ carbide having lattice parameters of $\mathrm{a}=0.2735 \mathrm{~nm}$ and $\mathrm{c}=$ $3680.4339 \mathrm{~nm}[30]$ can explain the measured peaks corresponding to $d_{\varepsilon-100}=0.2369 \mathrm{~nm}, \mathrm{~d}_{\varepsilon-103}=$ $3690.1234 \mathrm{~nm}$, and $\mathrm{d}_{\varepsilon-200}=0.1184 \mathrm{~nm}$. The $\eta-\mathrm{Fe}_{2} \mathrm{C}$ carbide having lattice parameters of $\mathrm{a}=0.4704$ $370 \mathrm{~nm}, \mathrm{~b}=0.4318 \mathrm{~nm}$, and $\mathrm{c}=0.2830 \mathrm{~nm}$ can also explain the measured peaks according to $\mathrm{d}_{\eta-011}$ 
$371=0.2367 \mathrm{~nm}, \mathrm{~d}_{\eta-230}=0.1228 \mathrm{~nm}$, and $\mathrm{d}_{\eta-022}=0.1183 \mathrm{~nm}$. Even the slight peak asymmetry (see

372 magnified insert in Figure 3) can be assigned to $\eta-\mathrm{Fe}_{2} \mathrm{C}$. Other carbides, like $\mathrm{Fe}_{3} \mathrm{C}, \mathrm{Fe}_{5} \mathrm{C}_{2}, \mathrm{Fe}_{7} \mathrm{C}_{3}$,

373 cannot explain the observed results and certainly are not present in the as-deposited Fe-C

374 coatings.

375 To test the suggestion of either $\varepsilon-\mathrm{Fe}_{2} \mathrm{C}$ or $\eta-\mathrm{Fe}_{2} \mathrm{C}$ carbides, XRD has been carried out under

376 various sample tilts and rotations, but no additional reflections or higher intensities could be

377 revealed. However, when tilting the sample about the angle $\psi$, the intensity of the $110 \alpha-F e$

378 lowers until the peak fully disappears at $\psi=12 \mathrm{deg}$ and the intensity of the peak, corresponding

379 to the d-spacing of $0.2360 \mathrm{~nm}$, does the same, thus, the intensity changes of both peaks are

380 correlated. This suggests a crystallographic orientation relation between $\alpha-\mathrm{Fe}$ and $\varepsilon-\mathrm{Fe}_{2} \mathrm{C}$ or $\eta-$

$381 \mathrm{Fe}_{2} \mathrm{C}$, respectively. This is further supported by the observation of a correlated peak shift

382 between $110 \alpha-\mathrm{Fe}$ and the supposed $100 \varepsilon-\mathrm{Fe}_{2} \mathrm{C}$ or $011 \eta-\mathrm{Fe}_{2} \mathrm{C}$, which occurs independent of the

383 coating thickness as mentioned above (cf. Table 2). The low intensities of measured XRD peaks

384 for carbides of $\varepsilon-\mathrm{Fe}_{2} \mathrm{C}$ or $\eta-\mathrm{Fe}_{2} \mathrm{C}$ suggest a low volume of carbides in the coating, and the rather

385 broad peak(s) further indicate that the corresponding carbide phase is nanocrystalline and might

386 be fine dispersed. In an attempt to locate these carbides, the embedded samples were re-polished

387 and etched with Murakami etchant for a dedicated SEM investigation, but no carbon-rich phase

388 could be resolved. In conclusion, despite the clear experimental evidence of a second phase and

389 the strong suggestion that it is associated with the formation of $\mathrm{Fe}_{2} \mathrm{C}$ carbides in the $\mathrm{Fe}-\mathrm{C}$

390 coatings, its final identification requires further investigations.

391 Independent of the nature of the not-yet clearly identified carbide, which is present in the as-

392 deposited $\mathrm{Fe}-\mathrm{C}$ coatings in addition to $\alpha-\mathrm{Fe}$, the carbide phase is expected to contribute

393 essentially to the high hardness of the coatings being in the order of that of martensitic steels.

394 Both $\varepsilon-\mathrm{Fe}_{2} \mathrm{C}$ and $\eta-\mathrm{Fe}_{2} \mathrm{C}$ carbides are associated with excellent mechanical properties [31-34],

395 but also the nanocrystallinity of ferrite grains and the detected additional elements of $\mathrm{H}$ and $\mathrm{O}$,

396 comprising the peculiar nature of electrodeposited coatings, contribute to the high hardness.

397 Being metastable carbides, the thermal stability of $\varepsilon-\mathrm{Fe}_{2} \mathrm{C}$ and $\eta-\mathrm{Fe}_{2} \mathrm{C}$ is expected to be limited,

398 which provides an additional possibility for further surface engineering by post-deposition

399 treatments. 
400 Already at fairly low coating thicknesses, the coating growth is fully dictated by the deposition

401 process and reproducible coatings can be deposited reliably. Final applications of the Fe-C

402 coatings utilizing their high hardness and related wear resistance, certainly aim at thick coatings

403 and the observed changes of the deposition rate might become relevant. The observed lowering

404 of the deposition rate after 120 minutes might be affected by several influences: changes of the

405 chemical concentrations in the electrolyte during the longer deposition times, a passivation of the

406 steel anode by a magnetite layer developed on its surface during deposition or an increase of the

407 hydrogen evolution at the cathode surface. The lowered deposition rate and the substantial

408 change in microstrain, which may be related to each other, had no apparent effect on the

409 macroscopic appearance of the Fe-C coatings having a dark shiny color, as well as neither on

410 their microstructure nor the resulting microhardness.

\section{V. CONCLUSION}

412 Fe-C coatings were electrochemically deposited from an iron-sulfate electrolyte with citric acid

413 as an additive. The very high microhardness of the as-deposited coatings and their chemical

414 composition containing $0.88 \mathrm{wt}$ pct $\mathrm{C}$ suggest a similarity to martensitic steel, but such rushed

415 terminology is not appropriate for the present Fe-C coatings. No tetragonal martensite has been

416 detected; instead, the $\mathrm{Fe}-\mathrm{C}$ coatings consist of carbon-free ferrite and a second phase of $\varepsilon-\mathrm{Fe}_{2} \mathrm{C}$

417 or $\eta-\mathrm{Fe}_{2} \mathrm{C}$ carbides. While these carbides are known to form during low-temperature tempering

418 of as-quenched martensite, for the present Fe-C coatings, it cannot be concluded whether the

419 carbides form directly during deposition or whether they result from an initial as-deposited phase

420 with a high driving force for carbide precipitation during continued deposition. The Fe-C

421 coatings are nanocrystalline and exhibit a strong fiber texture with a $<311>$ fiber axis in growth

422 direction. The chemical composition of the coatings, their microstructure, and the high

423 microhardness of almost $800 \mathrm{HV}$ have been observed to be independent of the coating thickness.

424 This indicates the strong impact of the deposition conditions on the coating growth and offers the

425 possibility for tailoring the microstructure and properties by further optimization of the

426 electrodeposition process.

427 The homogeneous and reproducible deposition process, resulting in reliable Fe-C coatings

428 independent of the applied coating thickness, allows for both the comparison of different

429 coatings and the adaption of the thickness to a given purpose or application, which is important 
430 for industry. Furthermore, the obtained understanding of the incorporation of co-deposited 431 carbon as fine carbides provide the essential prerequisite for a wide range of applications, where

432 the ability to deposit thick coatings with high hardness is very attractive. Further properties, like 433 adhesion, wear resistance, and corrosion resistance, as well as the coating's thermal stability, are 434 currently being investigated. One of the most critical properties is the oxidation resistance of 435 iron-based materials, but oxidation would only restrict the potential applications to lubricated 436 surfaces and not be a general hindrance for technical applications.

\section{ACKNOWLEDGMENTS}

440 The authors gratefully acknowledge OCAS NV, ArcelorMittal Global R\&D Gent (Belgium), a. 441 h. nichro Haardchrom (Denmark), and Fast Track - Societal Partnership (Denmark), funded by 442 the Innovation Fund Denmark (IFD), for financial support.

\section{REFERENCES}

445 [1] H.E. Cleaves, J.G. Thompson, The Metal - Iron, Alloys of Iron Research Monograph 446 Series, McGraw-Hill Book Company, New York and London, 1935, pp. 5-17.

447 [2] A.E. Tashkin, Russ. Eng. J., 1969, vol. 49, pp. 20-21.

448 [3] G.I. Morozov, V.I. Morozov, Met. Sci. Heat Treat., 1974, vol. 16, pp. 888-890.

449 [4] M. Schlesinger, M. Paunovic, M. Izaki, Modern Electroplating, 5th ed, John Wiley \& 450 Sons, Hoboken, New Jersey, 2010, pp. 309-326.

451 [5] A.S.M.A. Haseeb, Y. Hayashi, M. Masuda and M. Arita, Metall. Mater. Trans. B, 2002, 452 vol. 33, pp. 921-927.

453 [6] Y. Fujiwara, M. Izaki, H. Enomoto, T. Nagayama, E. Yamauchi, A. Nakae, J. Appl. $454 \quad$ Electrochem., 1998, vol. 28, pp. 855-862.

455 [7] Y. Fujiwara, T. Nagayama, A. Nakae, M. Izaki, H. Enomoto and E. Yamauchi, J. 456 Electrochem. Soc., 1996, vol. 143, pp. 2584-2590. 
457 [8] A.S.M.A. Haseeb, M.Z. Huq, Met. Finish., 1997, vol 95, pp. 30-34.

458 [9] M. Izaki, T. Omi, Metall. Mater. Trans. A., 1996, vol. 27, pp. 483-486.

459 [10] N. Miyamoto, K. Yoshida, M. Matsuoka, J. Tamaki, J. Electrochem. Soc., 2004, vol. 151, pp. C645-C648.

461 [11] M. Izaki, N. Miyamoto, A. Nakae, T. Hasegawa, S. Watase, M. Chigane, Y. Fujiwara, M. Ishikawa, H. Enomoto, J. Electrochem. Soc., 2002, vol. 149, pp. C370-C374.

463 [12] M. Panayotova, Surf. Coat. Technol., 2000, vol. 124, pp. 266-271.

464 [13] T. Müller, J. Grimwood, A. Bachmaier, T. Schöberlm R. Pippan, Metals, 2018, vol. 8(5) $465 \quad 363$

466 [14] S.D. Dahlgren, M.D. Merz, Metall. Mater. Trans., 1971, vol. 2, pp. 1753-1760.

467 [15] A. Weck, C.W. Sinclair, C.P. Scott, C. Maunder, J. Mater. Sci., 2002, vol. 47, pp. 6939$468 \quad 6947$.

469 [16] I. Jouanny, V. Demange, J. Ghanbaja, E. Bauer-Gosse, J. Mater. Res., 2010, vol. 25, pp. $470 \quad 1859-1869$.

471 [17] X. Zhao, R.J. Sanderson, L. MacEachern, R.A. Dunlap, Electrochimica Acta, 2015, vol. $472 \quad 170$, pp. 16-24.

473 [18] R. Winand, Hydrometallurgy, 1992, vol. 29, pp. 567-598.

474 [19] M. Paunovic, M. Schlesinger, Fundamentals of Electrochemical Deposition, 2nd ed, John 475 Wiley \& Sons, Hoboken, New Jersey, 2006, pp. 113-137.

476 [20] J.I. Langford. J. Appl. Cryst., 1978, vol. 11, pp. 10-14.

477 [21] T.H. de Keijser, J.I. Langford, E.J. Mittemeijer, A.B.P. Vogels, J. Appl. Cryst., 1982, vol. $478 \quad 15$, pp. 308-314.

479 [22] C. Esling, E. Bechler-Ferry, H.J. Bunge, J. Phys. Lettres, 1981, vol. 42, pp. 141-144.

480 [23] N. Miyamoto, S. Sakamoto, H. Tamura, M. Matsuoka, J. Tamaki, J. Electrochem. Soc., $481 \quad 2005$, vol. 152, pp. C488-C492. 
482 [24] D.A. Porter, K.E. Easterling, M.Y. Sherif, Phase transformations in metals and alloys, 483 2nd ed, Chapman \& Hall, New York, NY, 2009, pp. 382-396.

484 [25] G.A. Nematollahi, B. Grabowski, D. Raabe, J. Neugebauer, Acta Metall., 2016, vol. 111, $485 \quad$ pp. 321-334.

486 [26] Y. Hirotsu, S. Nagakura, Acta Metall., 1972, vol. 20, pp. 645-655.

487 [27] H.L. Yakel, Int. Met. Rev., 1985, vol. 30, pp. 17-40.

488 [28] S.W. Thompson, Mater. Charact., 2015, vol. 106, pp. 452-462.

489 [29] S.W. Thompson, Metallogr. Microstruct. Anal., 2016, vol. 5, pp. 367-383.

490 [30] H.K.D.H. Bhadeshia, Bainite in steels, 3th ed, Maney Publishing, Hanover Walk, Leeds $491 \quad 2015$, pp. 62.

492 [31] X.T. Deng, T.L. Fu, Z.D. Wang, R.D.K. Misra, G.D. Wang, Mater. Sci. Technol., 2016, $493 \quad$ vol. 32:4, pp. 320-327

494 [32] L. Hui, Z.Q. Chen, Z. Xie, C. Li, Stability, J. Supercond. Nov. Magn., 2018, vol. 31, pp. 495 353-364.

496 [33] X. Chong, Y. Jiang, J. Feng, J. Alloys Compd., 2018, vol. 745, pp. 196-211.

497 [34] A. Oila, C. Lung, S. Bull, J. Mater. Sci., 2014, vol. 49, pp. 2383-2390. 
499 Table 1: Thickness measurements and calculated average deposition rate.

\begin{tabular}{|c|c|c|}
\hline Deposition time $[\mathrm{min}]$ & Thickness $[\mu \mathrm{m}]$ & Average deposition rate $[\mu \mathrm{m} / \mathrm{min}]$ \\
\hline 30 & 8 & 0.27 \\
\hline 60 & 16 & 0.27 \\
\hline 120 & 30 & 0.25 \\
\hline 300 & 58 & 0.19 \\
\hline
\end{tabular}

500

501

502 Table 2: d-spacing [nm] obtained from peak profile fitting of XRD patterns with diffraction 503 angles $^{\circ} 2 \Theta$, as measured for Fe-C coatings (cf. Figure 3).

\begin{tabular}{|c|l|c|c|c|c|c|}
\hline${ }^{\circ} \Theta \Theta$ & Phase & hkl & Fe-C_ $8 \mu \mathrm{m}$ & Fe-C_16 $\mu \mathrm{m}$ & Fe-C_30 $\mu \mathrm{m}$ & Fe-C_58 $\mu \mathrm{m}$ \\
\hline 58.1 & & & $0.2360 \mathrm{~nm}$ & $0.2361 \mathrm{~nm}$ & $0.2366 \mathrm{~nm}$ & $0.2364 \mathrm{~nm}$ \\
\hline 68.6 & $\alpha$-iron & 110 & $0.2027 \mathrm{~nm}$ & $0.2031 \mathrm{~nm}$ & $0.2033 \mathrm{~nm}$ & $0.2032 \mathrm{~nm}$ \\
\hline 106.2 & $\alpha$-iron & 200 & $0.1430 \mathrm{~nm}$ & $0.1431 \mathrm{~nm}$ & & \\
\hline 137.6 & & & $0.1228 \mathrm{~nm}$ & $0.1228 \mathrm{~nm}$ & $0.1229 \mathrm{~nm}$ & $0.1228 \mathrm{~nm}$ \\
\hline 150.7 & & & $0.1183 \mathrm{~nm}$ & $0.1183 \mathrm{~nm}$ & $0.1184 \mathrm{~nm}$ & $0.1184 \mathrm{~nm}$ \\
\hline 156.7 & $\alpha$-iron & 211 & $0.1168 \mathrm{~nm}$ & $0.1169 \mathrm{~nm}$ & $0.1169 \mathrm{~nm}$ & $0.1169 \mathrm{~nm}$ \\
\hline
\end{tabular}


505 Table 3: Crystallographic texture of Fe-C coatings with varying thickness.

\begin{tabular}{|c|c|c|}
\hline Sample & Fiber axis $\langle u v w\rangle$ & Strength [m.r.d.] \\
\hline $\mathrm{Fe}-\mathrm{C} \_8 \mu \mathrm{m}$ & $\langle 311\rangle$ & 9.3 \\
\hline $\mathrm{Fe}-\mathrm{C} \_16 \mu \mathrm{m}$ & $\langle 311\rangle$ & 9.3 \\
\hline $\mathrm{Fe}-\mathrm{C} \_30 \mu \mathrm{m}$ & $\langle 311\rangle$ & 10.4 \\
\hline $\mathrm{Fe}-\mathrm{C} \_58 \mu \mathrm{m}$ & $\langle 311\rangle$ & 11.2 \\
\hline
\end{tabular}

506

507 Table 4: Integral breadth $\beta\left[{ }^{\circ} 2 \Theta\right]$, corrected for any instrumental effects, and corresponding 508 crystallite size D [nm] and microstrain $\varepsilon[\mathrm{rms}]$, as obtained from XRD profile analysis.

\begin{tabular}{|c|c|c|c|}
\hline Sample & $\beta\left[{ }^{\circ} 2 \Theta\right]$ & $\mathrm{D}[\mathrm{nm}]$ & $\varepsilon \cdot 10^{-3}[\mathrm{rms}]$ \\
\hline $\mathrm{Fe}-\mathrm{C} \_8 \mu \mathrm{m}$ & 1.6195 & 9.8 & 0.37 \\
\hline $\mathrm{Fe}-\mathrm{C} \_16 \mu \mathrm{m}$ & 1.9473 & 8.2 & 0.44 \\
\hline $\mathrm{Fe}-\mathrm{C} \_30 \mu \mathrm{m}$ & 2.0360 & 8.7 & 3.50 \\
\hline $\mathrm{Fe}-\mathrm{C} \_58 \mu \mathrm{m}$ & 2.0969 & 8.1 & 2.70 \\
\hline
\end{tabular}

509

510 Table 5: Microhardness of Fe-C coatings measured from the surface and cross section of the 511 coatings. *Cross sections with low coating thickness cannot be measured reliably.

\begin{tabular}{|c|c|c|}
\hline Sample & Surface - HV0.01 & Cross section - HV0.01 \\
\hline Fe-C_8 $\mu \mathrm{m}$ & $775 \pm 24$ & $*$ \\
Fe-C_16 $\mu \mathrm{m}$ & $780 \pm 25$ & $792 \pm 16$ \\
Fe-C_30 $\mu \mathrm{m}$ & $780 \pm 20$ & $789 \pm 14$ \\
Fe-C_58 $4 \mathrm{~m}$ & $775 \pm 16$ & \\
\hline
\end{tabular}

512 


\section{$513 \quad$ List of figures}

514 Figure 2: Cross section of sample Fe-C_ $58 \mu \mathrm{m}$. Ni-P corresponds to the amorphous substrate layer 515 on top of steel, while a $\mathrm{Ni}$ film protects the surface of the $\mathrm{Fe}-\mathrm{C}$ coating during metallographic 516 preparation. a) LOM image, b) SEM image.

518 Figure 2: GDOES depth profile measured for the sample Fe-C_16 $\mu \mathrm{m}$. The concentration of

519 carbon refers to the left y-axis, while measured intensities for hydrogen and oxygen refer to the 520 right $\mathrm{y}$-axis.

522 Figure 3: X-ray diffraction pattern of Fe-C coatings. (The maximum value of $160^{\circ} 2 \Theta$

523 corresponds to the upper limit of the measurement range and, therefore, the broad $\alpha-211$ cannot 524 be recorded completely.)

526 Figure 4: Pole figures of $\alpha$-iron as measured by XRD for the sample Fe-C_16 $16 \mathrm{~m}$.

528 Figure 5: Inverse pole figures in growth direction obtained by XRD measurements. 